\title{
Preparation of Tunable Wettability Polymer (Ionic Liquid) Brushes at Rough Substrate using Surface Initiated Atom Transfer Radical Polymerization
}

\author{
Kanjun Sun, Wu Yang,* Guofu Ma, Fei Wan, Jinzhang Gao, Ziqiang Lei and Hao Guo \\ Key Lab of Eco-environment Related Polymer Materials of MOE, College of Chemistry and \\ Chemical Engineering, Northwest Normal University, Lanzhou 730070, P.R. China
}

\begin{abstract}
Através da técnica de polimerização radicalar por transferência atômica (ATRP) foram preparadas novos polímeros tipo pente com molhabilidade ajustável (líquido iônico) de hexafluorfosfato poli[2-(1-butilimidazolino-3-ila)etila metacrilato $\left(\mathrm{PBIMH}-\mathrm{PF}_{6}^{-}\right)$, a partir de um substrato bruto modificado com uma camada iniciadora composta de brometo 2-bromoisobutirila. Várias técnicas de caracterização como elipsometria, medidas de ângulo de contato estático, espectroscopia fotoeletrônica de raios X (XPS) e microscopia de força atômica (AFM) foram utilizadas para caracterizar os filmes em cada etapa de modificação da superfície. Estudos cinéticos revelaram um aumento linear na espessura do filme polimérico em função do tempo de reação, indicando que o crescimento da cadeia a partir da superfície, é um processo cujo controle apresenta características de polimerização "viva". As medidas de molhabilidade indicaram que as interações de troca iônica podem ser usadas para alterar as características da superfície de hidrofilicidade para hidrofobicidade de forma reversível. O substrato bruto obtido por ataque químico exibiu uma melhor hidrofobicidade quando comparado à superfície lisa do substrato plano modificado com as mesmas cadeias poliméricas tipo pente (líquido iônico).
\end{abstract}

Using surface initiated atom transfer radical polymerization (ATRP), novel tunable wettability polymer (ionic liquid) brushes poly[2-(1-butylimidazolium-3-yl)ethyl methacrylate hexafluorophosphate] $\left(\mathrm{PBIMH}-\mathrm{PF}_{6}{ }^{-}\right)$from a rough substrate modified with an initiator layer composed of 2-bromoisobutyryl bromide was prepared. Various characterization techniques including ellipsometry, static water contact angle measurements, X-ray photoelectron spectroscopy (XPS), and atomic force microscope (AFM) were used to characterize the films for each surface modification step. Kinetic studies revealed a linear increase in polymer film thickness with reaction time, indicating that chain growth from the surface was a controlled process with a "living" characteristic. Wetting measurements indicated that ion exchanging interactions can be used to switch surface characteristics from hydrophilicity to hydrophobicity in a reversible manner. Compared with the smooth surface of the flat substrate modified with the same polymer (ionic liquid) brushes, the rough substrate by chemical etching exhibited better hydrophobicity.

Keywords: tunable wettability, polymer brushes, surface-initiated polymerization, ion exchanging, rough substrate

\section{Introduction}

Wettability is an important property of a solid surface depending on the surface free energy and surface roughness, and it is governed by both chemical composition and surface structure. ${ }^{1-5}$ Recently, control of surface wettability has attracted extensive interests ${ }^{6,7}$ because of its wide variety of applications, such as discrete liquid droplet manipulators, ${ }^{8}$ self-clean surfaces, ${ }^{9}$ tunable optical lenses, ${ }^{10}$ drug delivery and biomimetic

*e-mail: yangw@nwnu.edu.cn materials, ${ }^{11,12}$ microfabrication, ${ }^{13,14}$ and bioanalytical ${ }^{15}$ and microfluidic device ${ }^{16}$ with tunable properties.

Among the surface modification methods, grafting surfaces with polymer brushes provides a versatile way to modify surface properties, ${ }^{17-20}$ because of increasing the grafting density and immobilized tethering of polymer brushes on a solid substrate by performing an organic reaction with high efficiency ${ }^{21}$ including grafting a polymer chain through a monomer covalently linked to the surface ${ }^{22}$ and from a surface modified with polymerization initiators. ${ }^{23-25}$ Surfaceinitiated atom transfer radical polymerization (ATRP) is one 
of the most efficient grafting processes ${ }^{26-29}$ because it can be used to polymerize a wide range of vinyl monomers, does not require stringent conditions, and is tolerant of various functional groups and impurities that are detrimental to living anionic, cationic and some transition-metal-mediated polymerizations. ${ }^{30}$

Facile tunability of physicochemical properties of ionic liquids (ILs), particularly imidazolium ions ${ }^{31,32}$ bearing simple alkyl appendages as cations, has led to intense interest in ILs as an alternative of conventional organic solvents in a range of synthesis, catalysis, and electrochemistry. Recent developments include their uses for biopolymers, ${ }^{33}$ chemical sensors for specific ions, ${ }^{34}$ determination of acidity scale, ${ }^{35}$ formation of nanosized metal particles ${ }^{36}$ and hollow metal oxide microspheres ${ }^{37}$ and so on. However, there has been little study on poly (ionic liquid) based materials. We are currently seeking to develop novel poly (ionic liquid) brushes modified substrate surface. The availability of potentially hydrophobic and hydrophilic ILs attests to the ease in the manipulation of their physical properties. ${ }^{38,39}$

This paper aims at developing a novel and simple way to achieve tunable wettability switching surface by a chemical etching of the surface of silicon substrate and following modification with polymer (ionic liquid) via surface initiated ATRP. Reversible switching between hydrophilicity and hydrophobicity can be achieved by simply exchanging their counteranions. Such switchable surfaces have potential applications in functional materials and intelligent microfluidic switching.

\section{Experimental}

\section{Materials}

Ammonia hexafluorophosphate (Aldrich, 98\%), 3-aminopropyltriethoxysilane (APS, Kanto Chemical Co.), 2,6-di-tert-butyl-4-methylphenol (Aldrich, 98\%), 2-bromoisobutyryl bromide (Alfa Aesar), 1-butylimidazole and 2-chloroethanol (Aldrich, 98\%), other reagents were of analytical grades. Deionized water was used throughout. The silicon (111) wafers were purchased from Shanghai Wafer Work Corp.

\section{Characterizations}

The static water contact angles were determined by a KRUSS DSA100 contact angle goniometer. The thickness of polymer layer was measured with a spectroscopic ellipsometer (Gaertner model L116C). Morphological images of the substrate surfaces were obtained with an atomic force microscope (AFM) (Seiko Instruments Inc.) in a tapping mode.
The X-ray photoelectron spectroscopy (XPS) analysis was carried out on a PHI-5702 multifunctional XPS, using $\mathrm{AlK}_{\alpha}$ radiation as the exciting source at a measurement angle of $54^{\circ}$. The binding energies of the target elements were determined at a pass energy of $29.35 \mathrm{eV}$ and a resolution of $\pm 0.2 \mathrm{eV}$, using the binding energy of $\mathrm{C}_{1 \mathrm{~s}}$ at $284.6 \mathrm{eV}$ as the reference. Hydrogen nuclear magnetic resonance ( ${ }^{1} \mathrm{H}$ NMR) spectra were measured with an INOVA $400 \mathrm{MHz}$ spectrometer with DMSO- $d_{6}$ or $\mathrm{D}_{2} \mathrm{O}$ as solvent.

Silicon rough surface construction, hydroxylation and immobilization of the ATRP initiator

The smooth flat silicon was immerged into freshly prepared mixed acid solution $\left(2.4 \mathrm{~mol} \mathrm{~L}-1 \mathrm{HF}+15.0 \mathrm{~mol} \mathrm{~L}-1 \mathrm{HNO}_{3}\right)$ at room temperature for $8 \mathrm{~min}$, then rinsed with plenty of distilled water and followed by boiling water for $10 \mathrm{~min}$, then washed using distilled water, and dried under a stream of nitrogen.

Then the rough substrate was immersed in $\left(0.1 \mathrm{~mol} \mathrm{~L}^{-1}\right)$ $\mathrm{NaOH}$ aqueous solution for $10 \mathrm{~min}$ and subsequently in $\left(0.1 \mathrm{~mol} \mathrm{~L}^{-1}\right) \mathrm{HNO}_{3}$ for 10 min to generate surface hydroxyl groups. The rough substrate had been washed with an excess of distilled water and dried under a flow of nitrogen.

The hydroxylation rough substrate was put in anhydrous methanol solution which contained (100:5, v/v) APS for at least $10 \mathrm{~h}$ to obtain chemically bonded $-\mathrm{NH}_{2}$ groups on the surface. The surface was rinsed with dichloromethane, dried under a flow of nitrogen gas. It was them immersed in dry dichloromethane contained pyridine $(100: 5, \mathrm{v} / \mathrm{v})$, the polymerization initiator 2-bromoisobutyryl bromide was added dropwise at $0{ }^{\circ} \mathrm{C}$, and the mixture was maintained for $1 \mathrm{~h}$ at this temperature with electromagnetic stirring, then kept for $12 \mathrm{~h}$ at room temperature. The initiator modified silicon substrate was cleaned with dry dichloromethane, and dried under a nitrogen flow. This procedure was carried out according to a modification method of Sun et al. ${ }^{40}$ Above procedure is shown in Scheme 1.

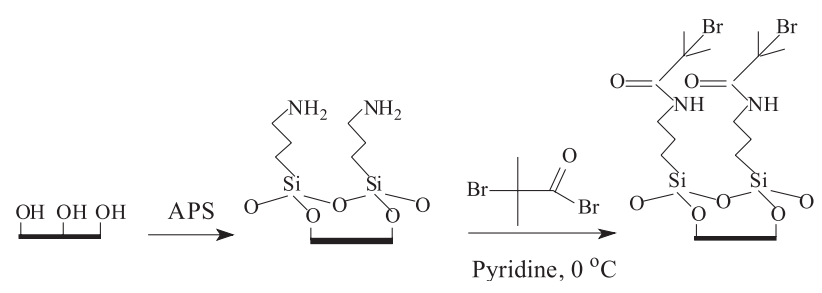

Scheme 1. Preparation procedure of initiator-modified silicon substrate surface.

Synthesis of the ionic liquid monomer

The synthesis of the ionic liquid monomer 2-(1-butylimidazolium-3-yl)-ethyl methacrylate hexafluorophosphate $(\mathrm{BIMH}) \mathrm{PF}_{6}{ }^{-}$was performed according 


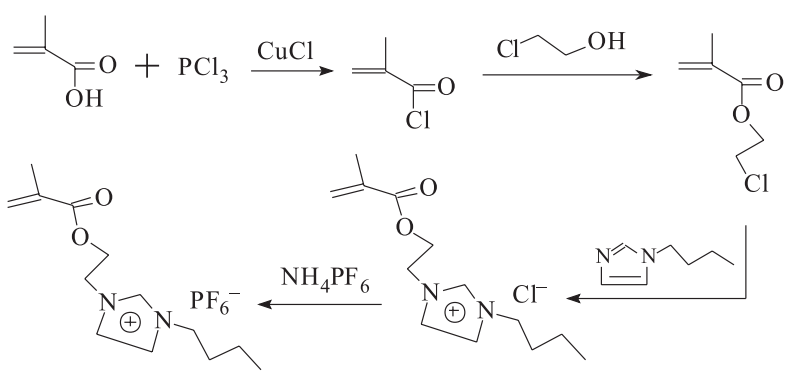

Scheme 2. Synthesic route of the ionic liquid monomer BIMH.

to slight modification procedure of Ding et al., ${ }^{41}$ and the synthesic route is shown in Scheme 2.

With cuprous chloride as catalyst, the reaction temperature was maintained at the boiling point of the system for $70 \mathrm{~min}$ at a feed ratio of 2:9 (the ratio of methacrylic acid to phosphorus trichloride). Then obtained methacryloyl chloride and 2-chloroethanol reacts to achieve 2-chloroethyl methacrylate. The mixture of 2-chloroethyl methacrylate, 1-butyl imidazole and a little amount of 2,6-di-tert-butyl-4 methylphenol was stirred at $40{ }^{\circ} \mathrm{C}$ for $48 \mathrm{~h}$ to yield a very viscous liquid, 2-(1-butylimidazolium 3-yl)-ethyl methacrylate chloride. Then a suspension of $\mathrm{NH}_{4} \mathrm{PF}_{6}$ in anhydrous acetonitrile was added and a white precipitate appeared. After the mixture was stirred for $48 \mathrm{~h}$ at room temperature, the sodium chloride precipitate was removed by filtration, and the filtrate was concentrated. The concentrated filtrate was diluted with methylene chloride $(250 \mathrm{~mL})$ and filtered through a silica gel column. By reduced pressure distillation methylene chloride was removed and the ionic liquid monomer 2-(1-butylimidazolium 3-yl)-ethyl methacrylate hexafluorophosphate was obtained as a viscous oil. ${ }^{1} \mathrm{H}$ NMR (400 MHz, DMSO) $\delta 8.391$ (s, 1H, N-C $\underline{H}-\mathrm{N}$ ), 7.478 (s, 1H, N-C $\underline{H}=\mathrm{CH}-\mathrm{N}), 7.303$ (s, 1H, N-CH=C프-N), 6.085 (s, $\left.1 \mathrm{H}, \mathrm{C}_{2}=\mathrm{CCH}_{3}\right), 5.729\left(\mathrm{~m}, 1 \mathrm{H}, \mathrm{C}_{2}=\mathrm{CCH}_{3}\right), 4.369$ (m, 2H, COO-C $\left.\underline{\mathrm{H}}_{2}-\mathrm{CH}_{2}-\mathrm{N}\right), 4.077$ (t, $2 \mathrm{H}, \mathrm{COO}-\mathrm{CH}_{2}-\mathrm{C}_{2}-\mathrm{N}$ ), $3.872\left(\mathrm{~m}, 2 \mathrm{H}, \mathrm{N}-\underline{\mathrm{H}}_{2}-\mathrm{C}_{3} \mathrm{H}_{7}\right), 1.906\left(\mathrm{~m}, 3 \mathrm{H}, \mathrm{CH}_{2}=\mathrm{CC} \underline{H}_{3}\right)$, $1.741\left(\mathrm{~m}, 2 \mathrm{H}, \mathrm{N}-\mathrm{CH}_{2}-\mathrm{CH}_{2} \mathrm{C}_{2} \mathrm{H}_{5}\right), 1.235\left(\mathrm{~m}, 2 \mathrm{H}, \mathrm{N}-\mathrm{C}_{2} \mathrm{H}_{4}-\right.$ $\left.\mathrm{C}_{2}-\mathrm{CH}_{3}\right), 0.898$ (t, 3H, N-C $\left.\mathrm{H}_{4} \mathrm{CH}_{2}-\mathrm{CH}_{3}\right) ;{ }^{13} \mathrm{C}$ NMR (400 $\left.\mathrm{MHz}, \mathrm{DMSO}-d_{6}\right): \delta(\mathrm{ppm}) 165.1\left(\mathrm{CH}_{2}=\mathrm{CCH}_{3}-\mathrm{COO}\right), 135.0(\mathrm{~N}-$ $\underline{\mathrm{CH}}-\mathrm{N}), 134.4\left(\mathrm{CH}_{2}=\underline{C C H}_{3}-\mathrm{COO}\right), 125.1\left(\underline{\mathrm{C}} \mathrm{H}_{2}=\mathrm{CCH}_{3}-\mathrm{COO}\right), 122.9$ $(\mathrm{N}-\underline{C} \mathrm{H}=\mathrm{CH}-\mathrm{N}), 119.5(\mathrm{~N}-\mathrm{CH}=\underline{C} \mathrm{H}-\mathrm{N}), 63.1\left(\mathrm{COO}-\underline{\mathrm{C}}_{2}-\mathrm{CH}_{2}-\mathrm{N}\right)$, $45.9\left(\mathrm{~N}-\mathrm{CH}_{2}-\mathrm{C}_{3} \mathrm{H}_{7}\right), 41.5\left(\mathrm{COO}-\mathrm{CH}_{2}-\underline{C H}_{2}-\mathrm{N}\right), 30.9\left(\mathrm{~N}_{-}-\mathrm{CH}_{2}-\underline{C H}_{2}-\right.$ $\left.\mathrm{C}_{2} \mathrm{H}_{5}\right), 17.9\left(\mathrm{~N}_{-} \mathrm{C}_{2} \mathrm{H}_{4}-\underline{C} \mathrm{H}_{2}-\mathrm{CH}_{3}\right), 16.7\left(\mathrm{CH}_{2}=\mathrm{C}^{-} \mathrm{H}_{3}-\mathrm{COO}\right), 12.1$ $\left(\mathrm{N}_{3} \mathrm{C}_{3} \mathrm{H}_{6}-\mathrm{CH}_{3}\right) ; \mathrm{MS}\left(\mathrm{ESI}^{+}\right) \mathrm{m} / \mathrm{z} 237\left[\mathrm{M}-\mathrm{PF}_{6}\right]^{+},\left(\mathrm{ESI}^{-}\right) \mathrm{m} / \mathrm{z} 145\left[\mathrm{PF}_{6}\right]^{-}$; HRMS (ESI ${ }^{+}$Found: 237.3217. Calc. for $\left[\mathrm{C}_{16} \mathrm{H}_{21} \mathrm{~N}_{2}\right]^{+}: 237.3215$.

\section{Results and Discussion}

\section{Characterization of functionalized surfaces}

Solution etching method was used to construct appropriate surface roughness on silicon substrate.

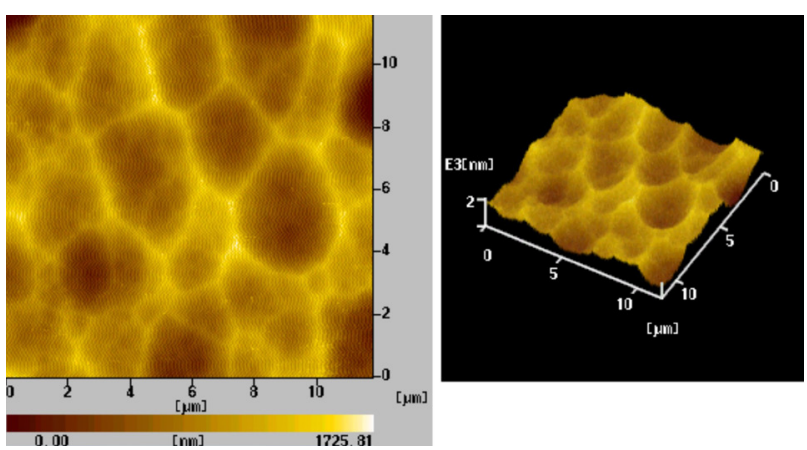

Figure 1. AFM topography and 3D image of the rough silicon substrate surface.

Surface morphology of rough silicon substrate is shown in Figure 1.

Figure 1 shows that some holes of $1-3 \mu \mathrm{m}$ have been etched in the substrate surface.

In order to carry out surface-initiated ATRP, initiator molecules must be at first introduced onto the substrate surface. Figure 2 shows the typical XPS survey spectrum and high-resolution elemental scan of $\mathrm{Br}_{3 \mathrm{~d}}$ and $\mathrm{N}_{1 \mathrm{~s}}$, which were recorded from the bromosilane initiator modified silicon surface. The $\mathrm{C}_{1 \mathrm{~s}}$ core-level spectrum of the initiator modified surface showed a peak at BEs of $284.4 \mathrm{eV}$. The $\mathrm{N}_{1 \mathrm{~s}}$ peak at the BEs of $398.8 \mathrm{eV}$ was attributed to the $\mathrm{O}=\mathrm{C}-\mathrm{N}$ species and $\mathrm{Br}_{3 \mathrm{~d}}$ peak at the $\mathrm{BEs}$ of $70.8 \mathrm{eV}$ resulted from $\mathrm{Br}-\mathrm{C}$. These results proved that bromosilane initiator has been successfully anchored on the silicon surface.

Preparation and characterization of PBIMH-PF ${ }_{6}$ brushes using a surface-initiated ATRP and tunning of the wettability by exchanging their counteranions

Copper chloride purified (0.092 mmol), 2,2-bipyridine purified $(0.184 \mathrm{mmol})$, and $\mathrm{BIMH}-\mathrm{PF}_{6}{ }^{-}(9.2 \mathrm{mmol})$ were charged into a Bunsen flask with branch pipe, which was then tightly sealed and degassed. Degassed acetonitrile $(1.6 \mathrm{~mL})$ was added with a degassed syringe. The mixture was bubbled with nitrogen for $15 \mathrm{~min}$, and then the beforehand prepared rough substrate modified with the surface initiator was added. The flask was immersed in an oil bath at $60^{\circ} \mathrm{C}$. At regular intervals, sample brushes were taken from the flask via a nitrogen-purged, and then were put into DMF to wash-up to remove physically absorbed polymer chains. After the polymer brushes were placed into a Soxhlet extractor to extract with DMF for $16 \mathrm{~h}$, they were dried in a stream of nitrogen and kept in a refrigerator.

The tuning of wettability of poly (ionic liquid) brushes was carried out by exchanging their counteranions and Scheme 3 showed a typical procedure for counteranion exchanging. 


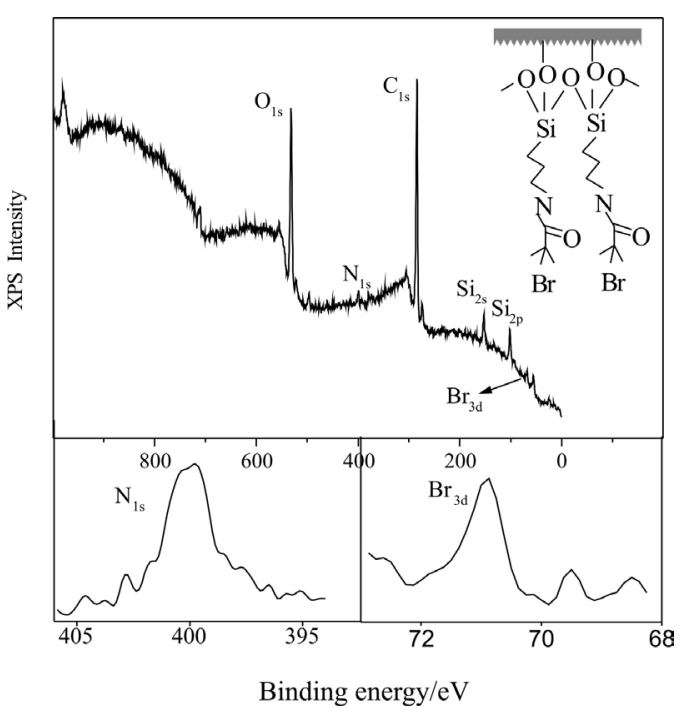

Figure 2. XPS survey spectrum and high-resolution elemental scan of $\mathrm{Br}_{3 \mathrm{~d}}$ and $\mathrm{N}_{1 \mathrm{~s}}$ of the bromosilane initiator modified silicon surface.
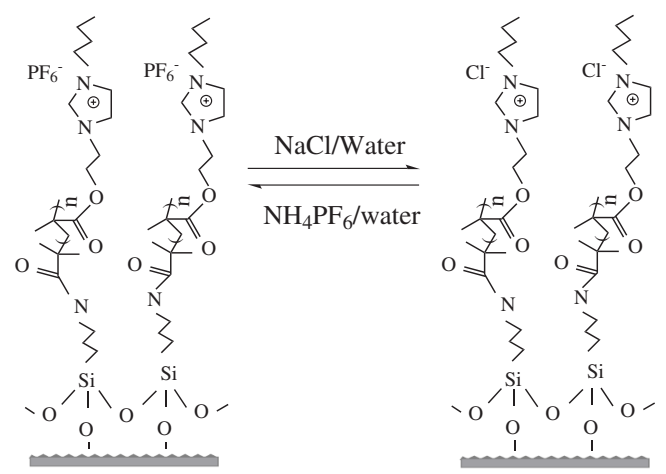

Scheme 3. Procedure of counteranion exchange of the polymer brushes PBIMH-PF ${ }_{6}^{-}$and PBIMH-Cl${ }^{-}$.

Figure 3 and Figure 4 respectively show that the typical XPS survey spectrum and high-resolution elemental scan at the silicon surface modified with $\mathrm{PBIMH}-\mathrm{PF}_{6}^{-}$ and PBIMH- $\mathrm{Cl}^{-}$brushes. In Figure 3 the peaks of $\mathrm{F}_{1 \mathrm{~s}}$ $(688.4 \mathrm{eV}), \mathrm{O}_{1 \mathrm{~s}}(533.6 \mathrm{eV}), \mathrm{N}_{1 \mathrm{~s}}(399.6 \mathrm{eV}), \mathrm{C}_{1 \mathrm{~s}}(285.6 \mathrm{eV})$, and $\mathrm{P}_{2 \mathrm{p}}(139.2 \mathrm{eV})$ were clearly found and the ratio of $[\mathrm{N}]:[\mathrm{F}]:[\mathrm{P}]$ was about 2.2:6.1:1.1, which was close to theoretical results. After exchanging their counteranions, the peak of $\mathrm{Cl}_{2 \mathrm{p}}$ (201.7 ev) appeared in Figure 4, whereas the peak of $\mathrm{F}_{1 \mathrm{~s}}$ disappeared in survey spectrum, which showed hexafluorophosphate had completely been exchanged with chloride ion. The $[\mathrm{Cl}]:[\mathrm{N}]$ ratio was about 0.9:2.0, which was consistent with theoretical values.

Figure 5 and 6 are respectively AFM topographies of the rough silicon substrate surface and the smooth flat silicon substrate modified with $\mathrm{PBIMH}-\mathrm{PF}_{6}{ }^{-}$polymer brushes. Figure 5 showed that the polymer brushes had homogeneously been grafted on silicon substrate surface and a micro/nanometric composite structure had been constructed. Grafted layer thickness was about $200 \mathrm{~nm}$

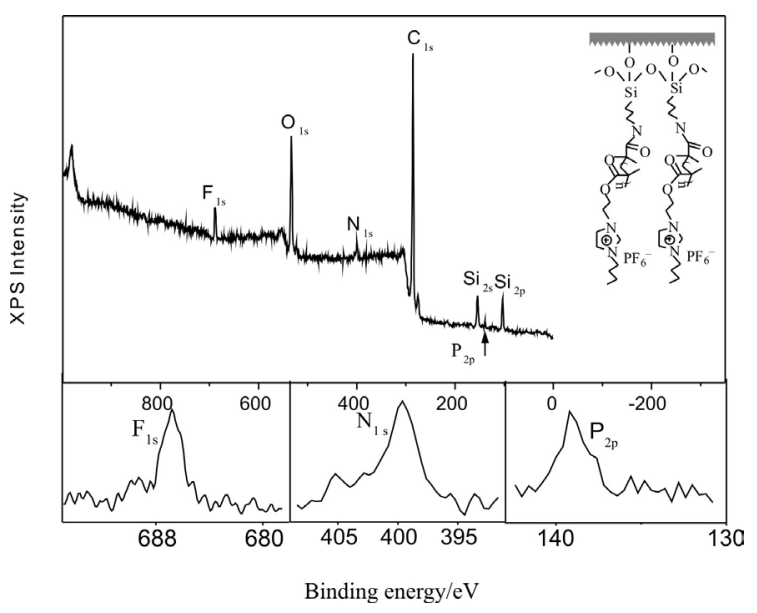

Figure 3. XPS survey spectrum and high-resolution elemental scan of $\mathrm{F}_{1 \mathrm{~s}}, \mathrm{~N}_{1 \mathrm{~s}}$ and $\mathrm{P}_{2 \mathrm{p}}$ of the PBIMH-PF${ }_{6}^{-}$modified silicon substrate surface.

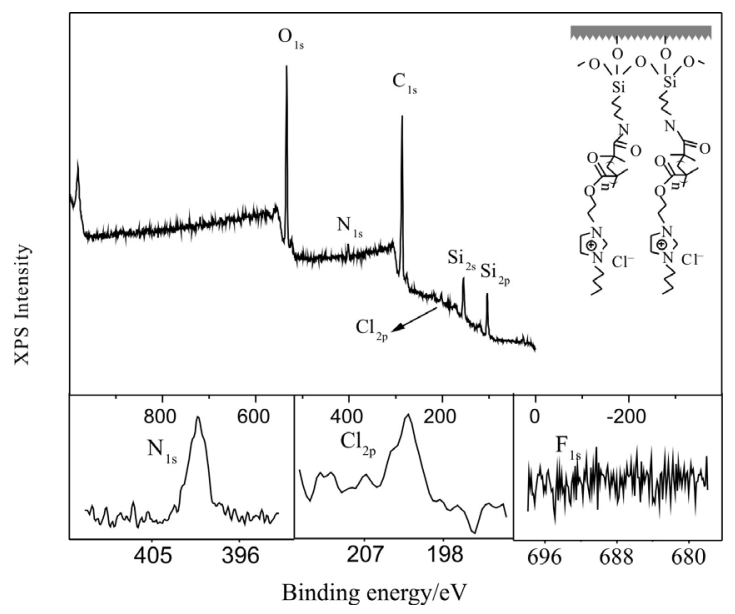

Figure 4. XPS survey spectrum and high-resolution elemental scan of $\mathrm{N}_{1 \mathrm{~s}}, \mathrm{Cl}_{2 \mathrm{p}}$ and $\mathrm{F}_{1 \mathrm{~s}}$ of the PBIMH-Cl- modified silicon substrate surface.

which was nearly consistent with ellipsometric result $(180 \mathrm{~nm})$. Figure 6 showed that the film thickness was also about $200 \mathrm{~nm}$ and the polymer brushes arrayed densely and homogeneously on the flat substrate.

Figure 7 shows typical water droplet shapes and corresponding contact angles (CA) on different substrates.
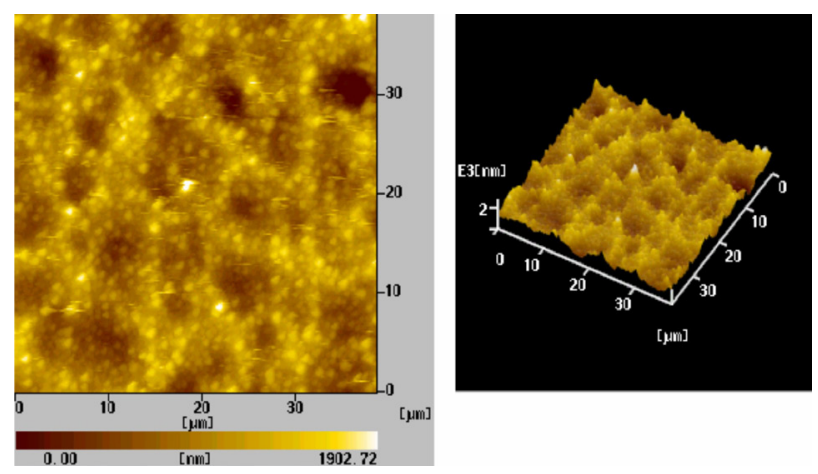

Figure 5. AFM topography and 3D image of the rough silicon substrate surface modified with polymer (ionic liquid) $\mathrm{PBIMH}-\mathrm{PF}_{6}{ }^{-}$brushes. 

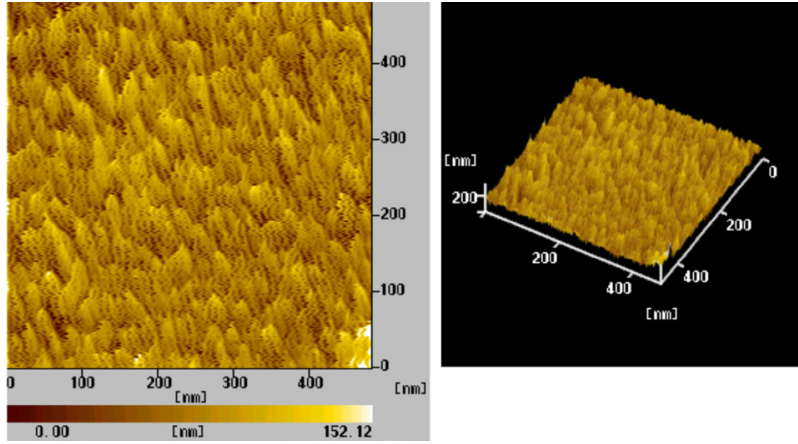

Figure 6. AFM topography and 3D image of the smooth silicon substrate surface modified with polymer (ionic liquid) $\mathrm{PBIMH}-\mathrm{PF}_{6}^{-}$brushes.

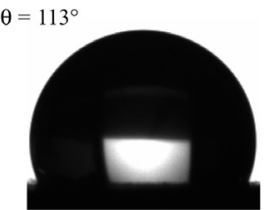

R-Si-PBIMH-PF ${ }_{6}^{-}$

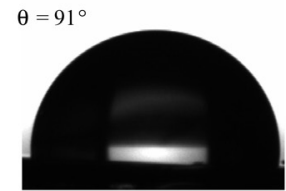

(b)

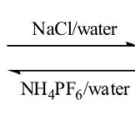

Si-PBIMH-PF 6

(a)

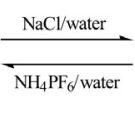

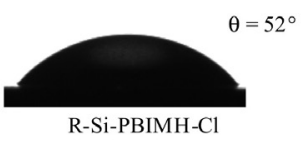

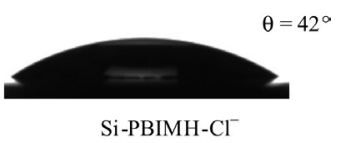

Si-PBIMH-Cl-
Figure 7. Photographs of water droplets on the polymer (ionic liquid) brushes modified surfaces when exchanged $\mathrm{PF}_{6}{ }^{-}$with $\mathrm{Cl}^{-}$. (a) On the rough silicon substrate; (b) On smooth silicon substrate.

It was found that through counteranion exchange the surface wettability had successfully been reversed and the rough $\mathrm{PBIMH}-\mathrm{PF}_{6}$ brushes surface $\left(\mathrm{R}-\mathrm{Si}-\mathrm{PBIMH}-\mathrm{PF}_{6}\right)$ had higher hydrophobicity than flat one (Si-PBIMH-PF $)_{6}$.

Figure 8 is the relationship of static water contact angle, reaction time and film thickness $(\mathrm{nm})$. From Figure 8 it was obviously seen that $\mathrm{CA}$ of $\mathrm{PBIMH}-\mathrm{PF}_{6}{ }^{-}$brushes increased with the reaction time but when it exceeded $24 \mathrm{~h}$ CA maintained a constant on the whole. However, $\mathrm{CA}$ of PBIMH-Cl- brushes did not changed nearly. It was also found that the surface wettability could be completely tuned reversibly only by exchanging counteranions.

Figure 8 also showed that the thickness of the polymer (ionic liquid) brushes linearly increased with the reaction time, indicating that the polymerization reaction was a "controlled/active" procedure.

\section{Conclusion}

Well-defined poly (ionic liquid) brushes with tunable wettability were successfully produced on the surface of rough silicon wafer by surface initiated ATRP

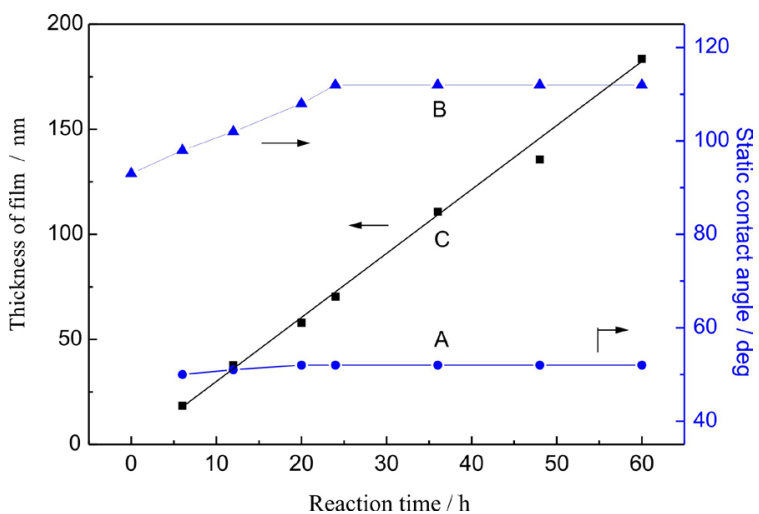

Figure 8. Relationship of static water contact angle / deg, reaction time / h and film thickness / nm. - - A: representation CA change of PBIMH-Cl$-\boldsymbol{\Delta}-\mathrm{B}$ : representation $\mathrm{CA}$ change of $\mathrm{PBIMH}-\mathrm{PF}_{6}{ }^{-} ;--\mathrm{C}$ : representation thickness of film.

polymerization. The tunable wettability of poly (ionic liquid) brushes can be achieved by exchanging their counteranions. Moreover, if the same two counteranions are sequentially replaced, the surface with tunable wettability, reversible switching between hydrophilicity and hydrophobicity can be easily obtained.

\section{Supplementary Information}

Supplementary data are available free of charge at http://jbcs.sbq.org.br, as PDF file.

\section{Acknowledgments}

The authors are grateful to National Natural Science Foundation of China (20873101) and Key Subject of Gansu Province, China for their financial supports.

\section{References}

1. Li, H.; Wang, X.; Song, Y.; Liu, Y.; Li, Q.; Jiang, L.; Zhu, D.; Angew. Chem., Int. Ed. 2001, 40, 1743.

2. Feng, L.; Li, S.; Li, H.; Zhai, J.; Song, Y.; Jiang, L.; Zhu, D.; Angew. Chem., Int. Ed. 2002, 41, 1221.

3. Feng, L.; Song, Y.; Zhai, J.; Liu, B.; Xu, J.; Jiang, L.; Zhu, D. Angew. Chem., Int. Ed. 2003, 42, 800.

4. Feng, L.; Li, S.; Li, Y.; Li, H.; Zhang, L.; Zhai, J.; Song, Y.; Liu, B.; Jiang, L.; Zhu, D.; Adv. Mater. (Weinheim, Ger.) 2002, 14, 1857.

5. Wang, R.; Hashimoto, K.; Fujishima, A.; Chikuni, M.; Kojima, E.; Kitamura, A.; Shimohigoshi, M.; Watanabe, T.; Nature 1997, 388, 431.

6. Lahann, J.; Mitragotri, S.; Tran, T.; Kaido, H.; Sundaram, J.; Choi, I. S.; Hoffer, S.; Somorjai, G. A.; Langer, R.; Science 2003, 299, 371. 
7. Yu, X.; Wang, Z.; Jiang, Y.; Shi, F.; Zhang, X.; Adv. Mater. (Weinheim, Ger.) 2005, 17, 1289.

8. Paik, P.; Pamula, V. K.; Pollack, M. G.; Fair, R. B.; Lab Chip 2003, 3, 28.

9. Cheng, Y. T.; Rodak, D. E.; Wong, C. A.; Hayden, C. A.; Nanotechnology 2006, 17, 1359.

10. Kuiper, S.; Hendriks, B. H. W.; Appl. Phys. Lett. 2004, $85,1128$.

11. Galaev, I. Y.; Mattiasson, B.; Trends Biotechnol. 1999, 17,335 .

12. Aksay, I. A.; Trau, M.; Manne, S.; Honma, I.; Yao, N.; Zhou, L.; Fenter, P.; Eisenberger, P. M.; Gruner, S. M.; Science 1996, 273, 892 .

13. Gleiche, M.; Chi, L. F.; Fuchs, H.; Nature 2000, 403, 173.

14. Tan, J. L.; Tien, J.; Chen, C. S.; Langmuir 2002, 18, 519.

15. Nath, N.; Chilkoti, A.; Adv. Mater. (Weinheim, Ger.) 2002, 14, 1243.

16. Rohr, T.; Ogletree, D. F.; Svec, F.; Fréchet, J. M. J.; Adv. Funct. Mater. 2003, 13, 264.

17. Zhao, B.; Brittain, W. J.; Prog. Polym. Sci. 2000, 25, 677.

18. Edmondson, S.; Osborne, V. L.; Huck, W. T. S.; Chem. Soc. Rev. 2004, 33, 14.

19. Motornov, M.; Sheparovych, R.; Katz, E.; Minko, S.; ACS Nano. 2008, 2, 41.

20. Zhou, F.; Huck, W. T. S.; Phys. Chem. Chem. Phys. 2006, 8,3815 .

21. Gao, H.; Matyjaszewski, K.; J. Am. Chem. Soc. 2007, 129, 6633 .

22. Buchmeiser, M. R.; Sinner, F.; Mupa, M.; Wurst, K.; Macromolecules 2000, 33, 32.

23. Prucker, O.; Ruhe, J.; Macromolecules 1998, 31, 592.

24. Wu, T.; Efimenko, K.; Genzer, J.; J. Am. Chem. Soc. 2002, 124, 9394

25. Zhai, G.; Kang, E. T.; Neoh, K. G.; Macromolecules 2004, 37, 7240 .
26. Matyjaszewski, K.; Miller, P. J.; Shukla, N.; Immaraporn, B.; Gelman, A.; Luokala, B. B.; Siclovan, T. M.; Kickelbick, G. ; Vallant, T.; Hoffmann, H.; Pakula, T.; Macromolecules 1999, 32, 8716.

27. Tsarevsky, N. V.; Matyjaszewski, K.; Chem. Rev. 2007, 107, 2270.

28. Zhang, M.; Liu, L.; Wu, C.; Fu, G.; Zhao, H.; He, B.; Polymer 2007, 48, 1989.

29. Tang, H.; Tang, J.; Ding, S.; Radosz, M.; Shen, Y.; J. Polym. Sci., Part A: Polym. Chem. 2005, 43, 1432.

30. Patten, T. E.; Matyjaszewski, K.; Adv. Mater. (Weinheim, Ger.) 1998, 10, 901.

31. Lee, S.; Chem. Commun. 2006, 1049.

32. Lee, B. S.; Chi, Y. S.; Lee, J. K.; Choi, I. S.; Song, C. E.; Namgoong, S. K.; Lee, S.; J. Am. Chem. Soc. 2004, 126, 480.

33. Kimizuka, N.; Nakashima, T.; Langmuir 2001, 17, 6759.

34. Ho, H. A.; Leclerc, M.; J. Am. Chem. Soc. 2003, 125, 4412.

35. Thomazeau, C.; Olivier-Bourbiou, H.; Magna, L.; Luts, S.; Gilbert, B.; J. Am. Chem. Soc. 2003, 125, 5264.

36. Dupont, J.; Fonseca, G. S.; Umpierre, A. P.; Fichtner, P. F. P.; Teixeira, S. R.; J. Am. Chem. Soc. 2002, 124, 4228.

37. Nakashima, T.; Kimizuka, N.; J. Am. Chem. Soc. 2003, 125, 6386.

38. Swatloski, R. P.; Visser, A. E.; Matthew Reichert, W.; Broker, G. A.; Farina, L. M.; Holbrey, J. D.; Rogers, R. D.; Chem. Commun. 2001, 2070.

39. He, X. Y.; Yang, W.; Pei, X. W.; Macromolecules 2008, 41, 4615.

40. Sun, T.; Wang, G.; Feng, L.; Liu, B.; Ma, Y.; Jiang, L.; Zhu, D.; Angew. Chem., Int. Ed. 2004, 43, 357.

41. Ding, S.; Tang, H.; Radosz, M.; Shen, Y.; J. Polym. Sci., Part A: Polym. Chem. 2004, 42, 5794.

Submitted: April 21, 2010 Published online: October 26, 2010 


\title{
Preparation of Tunable Wettability Polymer (Ionic Liquid) Brushes at Rough Substrate Using Surface Initiated Atom Transfer Radical Polymerization
}

\author{
Kanjun Sun, Wu Yang, * Guofu Ma, Fei Wan, Jinzhang Gao, Ziqiang Lei and Hao Guo
}

Key Lab of Eco-environment Related Polymer Materials of MOE, College of Chemistry and Chemical Engineering, Northwest Normal University, Lanzhou 730070, P.R. China

The ${ }^{13} \mathrm{C}$ NMR data/spectrum of ionic liquid monomer 2-(1-butylimidazolium 3-yl)-ethyl methacrylate hexafluorophosphate.

${ }^{13} \mathrm{C}$ NMR (400 MHz, DMSO- $\left.d_{6}\right): \delta(\mathrm{ppm}) 165.1\left(\mathrm{CH}_{2}=\mathrm{CCH}_{3}-\underline{C O O}\right), 135.0(\mathrm{~N}-\underline{C} \mathrm{H}-\mathrm{N})$, $134.4\left(\mathrm{CH}_{2}=\mathrm{CCH}_{3}-\mathrm{COO}\right), 125.1\left(\underline{\mathrm{CH}}_{2}=\mathrm{CCH}_{3}-\mathrm{COO}\right), 122.9(\mathrm{~N}-\underline{\mathrm{C}} \mathrm{H}=\mathrm{CH}-\mathrm{N}), 119.5$ $(\mathrm{N}-\mathrm{CH}=\underline{\mathrm{CH}}-\mathrm{N}), 63.1\left(\mathrm{COO}-\underline{\mathrm{C}} \mathrm{H}_{2}-\mathrm{CH}_{2}-\mathrm{N}\right), 45.9\left(\mathrm{~N}-\underline{\mathrm{C}} \mathrm{H}_{2}-\mathrm{C}_{3} \mathrm{H}_{7}\right), 41.5\left(\mathrm{COO}-\mathrm{CH}_{2}-\underline{\mathrm{C}} \mathrm{H}_{2}-\mathrm{N}\right), 30.9$ $\left(\mathrm{N}-\mathrm{CH}_{2}-\underline{\mathrm{C}} \mathrm{H}_{2}-\mathrm{C}_{2} \mathrm{H}_{5}\right), 17.9\left(\mathrm{~N}-\mathrm{C}_{2} \mathrm{H}_{4}-\underline{\mathrm{CH}_{2}}-\mathrm{CH}_{3}\right), 16.7\left(\mathrm{CH}_{2}=\mathrm{C} \underline{C} \mathrm{H}_{3}-\mathrm{COO}\right), 12.1\left(\mathrm{~N}^{-} \mathrm{C}_{3} \mathrm{H}_{6}-\underline{C} \mathrm{H}_{3}\right)$.
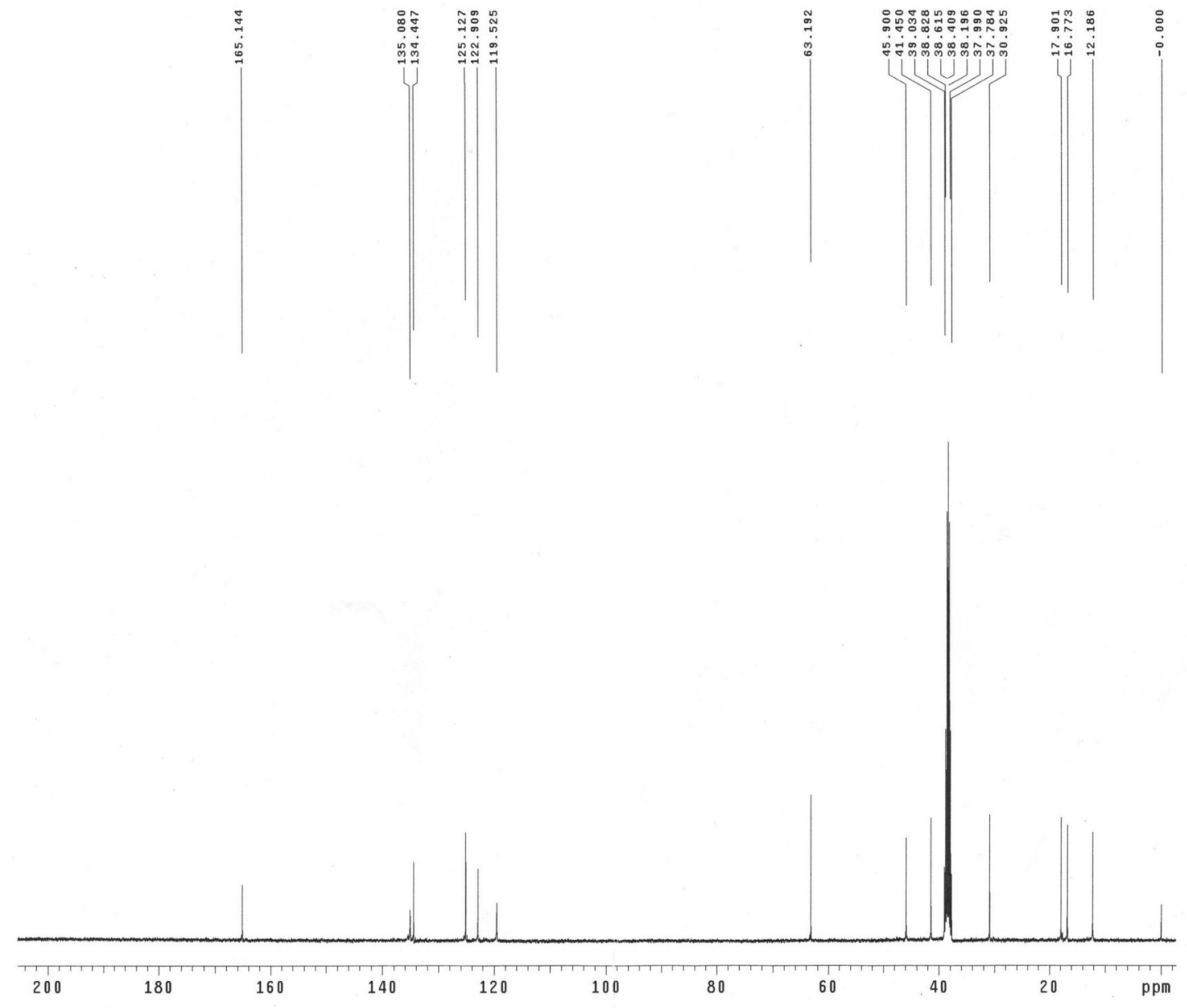

Figure S1. ${ }^{13} \mathrm{C}$ NMR spectrrum of ionic liquid monomer 2-(1-butylimidazolium 3-yl)-ethyl methacrylate hexafluorophosphate.

*e-mail: yangw@nwnu.edu.cn 